\title{
MEANS OF EXPRESSING GRATITUDE IN ENGLISH AND BULGARIAN - PRAGMATIC DIMENSIONS
}

\author{
Deyana Peneva ${ }^{1}$
}

\begin{abstract}
The paper investigates different ways and means of indicating gratitude exploited in English and Bulgarian. It basically focuses on a number of thanking situations, strategies and expressions with respect to use, politeness orientation and specificities. A division is further made between thanks, appreciation and gratitude. The aim of the article is to present the English patterns of speech acts of thanking in context-dependent speech situations and the challenges to learners when being exposed to input settings similar to the linguistic reality of the target community. The paper also dwells on the disparities and inaccuracies which may occur between the learners' native pragmatic knowledge and the expressions of gratitude which are most likely to be uttered by native speakers of English.
\end{abstract}

Keywords: context, gratitude, politeness, pragmatics, thanks

\section{Introduction}

The paper investigates ways of expressing gratitude (used as a broad term) in English and Bulgarian. It focuses on a three-dimensional analysis which makes a difference between thanks, gratitude and appreciation and examines the similarities and discrepancies between the data elicited by a corpus-driven research.

Data were collected from BNC (British National Corpus 2015-17) in which all cases of gratitude presented in a public debate TV format were extracted and classified. Since there is not a Bulgarian national corpus in this sphere of pragmatic research the Bulgarian database was collected via computer-based examination of tape-scripts from 20 consecutive public debate TV programs (Referendum and Paths on BNT 1 TV channel - Nov 2018-Feb 2019). The participants in both corpora are English and Bulgarian native speakers from different professional spheres of life (university professors, doctors, architects, managers and others) hence, in the discussions the interlocutors share similar social variables in order to be competent in a polemic setting. Though considerable similarities were revealed, there are certain cross-cultural disparities identified in terms of gratitude perception, thanks awareness and appreciation interpretation.

1. Assistant Prof., PhD at at Shumen University, Department of English Studies, Shumen, Bulgaria, e-mail: d.peneva@shu.bg 
Apart from this, the linguistic material under examination shows deviations in grammatical structures and syntactic patterns.

The article focuses specifically on three expressions of gratitude in the English language, namely, I am thankful, I am grateful and I appreciate and their respective translations in Bulgarian. Additionally, the syntactic patterns are identified and discussed in both corpora. Last but not least in importance is the pragmatics of the utterances in TV debates.

\section{Previous research in the field}

In recent years the number of research works regarding the issue of speech acts in intercultural surroundings has piled up dramatically due to the fact that scholars analysing international communication need to better understand the linguistic models in expressing politeness functions. That, in its part, asks for a proper and adequate expertise in communicative acts. The pragmatics of speech acts of thanking, though still nascent, now turns to be a fast-developing area of research and analysis with its specific illocutionary force and concrete implications starting from Searle (Searle, 1969) and Leech (Leech, 1983), who investigate thanks in general, going further with cross-cultural examinations (Ahar, 2011; Einstein \& Bodman, 1993; Mahdi, 2010). Particularly, there is not an in-depth comparative investigation with respect to English and Bulgarian thanks strategies and their respective cultural aptitudes and connotations. The speech acts of gratitude are subsumed under the set of expressive illocutionary acts in Speech act theory (Bach, 2004) in that they illustrate a psychological state or sincerity condition of the communicative act where the speaker reacts positively to the hearer who carried out an act which in some way was favourable or beneficial to the hearer (Searle, 1969). In this sense, the act of thanking is considered to be a counter effect or action which has been affected by a previous or current activity by the addressee. Additionally, expressions of gratitude bear a high level of politeness as they aim to maintain the social harmony and balance of respect to either party in the interaction. According to politeness theory (Bach, 2004) utterances of gratitude are regarded as negative face-threatening acts (FTAs) limiting the hearer's personal freedom (Thomas, 1986). From a psychological point of view, positive face-threatening acts are supposed to add something, whereas negative ones 'take something away". Positive FTAs add closeness and warm feelings between the interlocutors, whereas in the case of negative FTAs boundaries, hierarchy and respect are established (Bach, 2004).

The choice of utterance depends also on the relationship between the (oral) text producer (speaker) and the text receiver (hearer) (Aleksandrova, 2017). By saying 'Thank you', for example, the speaker acknowledges that the hearer you are thanking is an independent individual with his/ her own needs who is held in 
high respect by the speaker. That is quite the reverse of warmth and attachment (Eisenstein \& Bodman, 1986).

Most of the rules we follow in expressive speech acts are a form of etiquette and strategies of negative politeness which are hearer-oriented rather than speakeroriented.

\section{Research questions}

The paper collects material for analysis taken from BNC of spoken language in public debate shows and a series of Bulgarian TV programs in a similar format, settings and participants. The English corpus consists of 519 examples while the Bulgarian set of data is represented by 169 utterances. The phrases in both languages begin with a subject in the first person singular, Present Simple tense though the succeeding word, which bears the semantic meaning of gratitude, may not be represented by the same part of speech. There are certain questions that the article attempts to answer:

1) What are the favoured gratitude patterns in both sets of data?

2) To what extent do Bulgarian representatives differ from English native speakers in their pragmatic manifestation and politeness strategies?

\section{Methods}

The paper classifies the linguistic material by following the grammatical structures of the performative entries in the two languages.

In connection with the identification and examination of the linguistic items in patterns Quantitative and qualitative corpus analysis (following Biber, Conrad \& Reppen, 1998) is used, which is both corpus-based and corpus-driven (Tognini-Bonelli, 2001). In regard to the former (corpus-based), the corpus database serves to validate or refute, or add to politeness theory, while the latter approach (corpus-driven) prioritizes on the linguistic constructs which emerge from analysis of a corpus.

\section{Data analysis}

The analysis is three-dimensional in that it observes the grammatical, lexicosemantic and pragmatic aspects of the respective entries in English and Bulgarian.

Both corpora contain a total number of 688 utterances, 519 of English origin, 169 from the Bulgarian source. They are further subdivided into three main groups according to the three phrases under observation. 


\subsection{Expressions of gratitude - English corpus (EC)}

The three expressions explored in the present paper are I am thankful, I am grateful and I appreciate which are presented in the table below with their percentage rates:

Table 1. Case distribution of gratitude expressions in EC

\begin{tabular}{|c|c|c|}
\hline expression & number of cases & percentage rate \\
\hline I am thankful & 83 & $15.99 \%$ \\
\hline I am grateful & 280 & $53.94 \%$ \\
\hline I appreciate & 156 & $26.9 \%$ \\
\hline Total & 519 & $100 \%$ \\
\hline
\end{tabular}

There are 83 I am thankful cases identified in the corpus, which stands for $15.99 \%$ of the total, that is well under fifth of all gratitude utterances in English. I am grateful gains prominence with 280 examples which occupy more than half of all extracted phrases. I appreciate is present with 156 utterances which is approximately a quarter of the total number of occurrences.

\section{$>$ I am thankful}

The performative entry thankful is a content word which possesses the specific features of an adjective being of two-morpheme structure: a root morpheme and a suffix - ful. The latter serves not only as a derivational marker but also adds to the semantic meaning of the root morpheme. The suffix -ful comprises several meanings: 'characterized by, having the qualities of 'full of' (The New Oxford Dictionary, 2014). In general, the suffix implies the aspect of adding a quality or ability - full of thanks.

The adjective thankful in itself reveals two basic semantic meanings:

- pleased and relieved. Ex. ... I am thankful that the meeting is over... (2016)

- expressing gratitude and relief. Ex. ... I am thankful to John Brinkman ... for her remarkable work on ... /2017/

For the purposes of the current research only the second lexical meaning is regarded in the analysis as the first one does not bear the semantics of gratitude.

Syntactically the expression becomes explicit in three basic patterns, namely:

1. I am thankful + to /infinitive/:

1a: I am thankful + to /inf. $/+N P$

1b: I am thankful + to /inf. $/+V P$

1c: I am thankful + to /preposition/ + NP + for/preposition/ + NP/VP/gerund/

2. I am thankful + for/preposition/ 
2a: I am thankful + for $+N P$

2b: I am thankful + for + what-clause

\section{I am thankful + that + clause}

With respective number of occurrences illustrated in the table below:

Table 2. Case distribution of 'thankful' expressions in EC

\begin{tabular}{|l|l|l|}
\hline expression & number of cases & percent \\
\hline 1a: I am thankful to + VP & 2 & $0.38 \%$ \\
\hline 1b: I am thankful to + NP & 10 & $1.92 \%$ \\
\hline $\begin{array}{l}\text { 1c: I am thankful to + NP +for + NP/ } \\
\text { VP /gerund/ }\end{array}$ & 16 & $3.08 \%$ \\
\hline 2a: I am thankful for + NP & 51 & $9.82 \%$ \\
\hline 2b: I am thankful for + what-clause & 1 & $0.19 \%$ \\
\hline 3: I am thankful + that-clause & 3 & $0.57 \%$ \\
\hline Total & 83 & $15.99 \%$ \\
\hline
\end{tabular}

There are two cases in which the phrase is succeeded by a to-infinitive verbal form. With respect to its pragmatic meaning, the aspects of feeling glad and pleased become more distinct whereas the aspect of gratitude comes second in prominence. For example:

ex. ... I am thankful to be in a position to do something about this ...

Actually, there is no obvious manifestation of a real act of thanking someone for a favour or other activity. It sounds more as a feeling of relaxation or satisfaction to comfort oneself.

As for the next structure 1b: I am thankful to $+N P$, the noun phrase refers to a person and in real-life situations it corresponds to the addressee, whom the speaker is thanking. There are no pragmatic deviations from the semantic content, though obviously judging by the number of cases identified in the corpus, it does not come first in the scale of preference and practical usage in $\mathrm{TV}$ debate format programmes.

The third sub-pattern 1c:I am thankful + to/preposition/ + NP + for/preposition/ $+V P / g e r u n d /$ follows a rather complicated grammatical where the preposition is followed by a noun phrase with the semantic features [+animate; + person]/, after which comes the preposition for in a combination with either a NP or a gerundial verbal element. For instance:

ex. ... I am thankful to you for giving me this opportunity of telling ...

The lexical items which follow the preposition for indicate the reason why the speaker is performing the communicative act of thanking; the act which in some way is or has been favourable to the addresser. Pragmatically, although there is a case for saying that the exact pattern ranks first in preference compared to 
the former two sub-structures, we cannot make generalizations of its practical prominence since all three derivational sub-patterns are of limited occurrence in the corpus.

Regarding pattern 2: I am thankful for, it depicts two syntactic sub-structures: $\mathrm{NP}$; + what-clause. 2a: I am thankful + for $+N P$ gains significant prominence with 51 extracts over pattern $2 b$ with only one example extracted from the corpus. Similar to pattern 1c the NP implies the idea of an explanation or account of the act which was/has been in favour to the speaker:

ex.... I am thankful for Michael Anderson's extensive knowledge and generosity ...

The last syntactic structure 3: I am thankful + that-clause is present with three cases in the database with a that-clause suggesting an explanation or account for the reason for the act of thanking.

In all, I am thankful syntactic patterns comprise well over a fifth of all gratitude expressions with a prevalence of the sub-pattern I am thankful for $+N P$. Obviously, for English native speakers it is more typical to give explanation or communicate what they are thankful for rather than indicate who the speaker is thanking (to). This, on its part, confirms the negative politeness orientation that is associated with thanks speech acts as the speaker preserves his/her personal autonomy without explicit emotional markers. The pattern sounds distant, void of sentiment, formulaic, routinized. And as it is seen, it is not among the most typical gratitude expressions in debate TV programmes (see the table above).

\section{$>$ I am grateful}

With the largest number of occurrences, the pattern I am grateful follows an almost identical grammatical behaviour to the I am thankful pattern. The performative adjective grateful has a similar morphological structure in that it is a two-morpheme adjective with a root grate (from old Latin gratus - pleasing) and a derivational suffix - ful.

With a view to semantics, the entry is synonymous to the adjective thankful in that the same meanings characterize it: 1. pleasing to the mind or senses; agreeable or welcome; refreshing, and 2. expressing or actuated by gratitude; showing or expressing thanks to benefits received especially to another person (The New Oxford Dictionary 2014). The second meaning is under consideration in the article.

Grammatically (syntactically), the performative adjective can add prepositional phrases:

4a: I am grateful+ to /preposition/ $+N P$

ex. ... I am grateful to Katherine Borland and Diane Tye for the opportunity ... 
4b: I am grateful + for $+N P$

ex.... I am grateful for the comments of Dominique Tobbell and the anonymous reviewers ...

Although the adjective could also add infinitive verbal forms, this syntactic structure is excluded from the survey since it refers to the first semantic meaning of the entry.

The number of cases for the respective patterns is illustrated in the table below:

Table 3. Case distribution of 'grateful' expressions in EC

\begin{tabular}{|l|l|l|}
\hline expression & number of cases & percent \\
\hline 4a: I am grateful to + NP & 213 & $41.04 \%$ \\
\hline 4b: I am grateful for + NP & 67 & $12.2 \%$ \\
\hline Total & 280 & $53.94 \%$ \\
\hline
\end{tabular}

Actually, the overall number of all grateful expressions comprises the impressive 280 examples, well over half of all expressions of gratitude with 213 cases for 4a: I am grateful + to $+N P$ structure and 67 occurrences of $4 \mathrm{~b}:$ I am grateful + for $+N P$ sub-pattern.

Turning to $4 \mathrm{a}$ first, the main entry /grateful/ is followed by the preposition to which asks for a NP, the latter denoting a person. While in the case of $4 \mathrm{~b}$ the adjective grateful is succeeded by the preposition for plus a noun phrase with semantic features [- animate; -human], hence it is a noun which falls into the group of abstract nouns which refer to concepts or entities that cannot be perceived physically but mainly refer to conditions, ideas. In the given paper the most common abstract nouns after the preposition for are attention, concern, support, opportunity, suggestion, guidance, answer.

When analyzing the usage of the performative adjective several implicatures were noticed:

- the performative entry is used mainly in a formal register compared to more informal management of thankful;

- grateful refers to an internal feeling of thankfulness coming out from within and may be considered more expressive than thankful, which in turn, sounds slightly void of emotion, less expressive;

- grateful comes as an emotional response to an utterance or series of utterances performed by the other interlocutor in the speech situation; 


\section{$>$ I appreciate}

In relation to I appreciate expressions, 156 utterances were found in the corpus, which make well over a quarter of all gratitude phrases in the database. In contrast to the above performative entries, appreciate is not an adjective, but a verb.

With reference to its semantics, it could appear that it bears the content meaning of thankful and the emotional contour of grateful but adds an extra semantic aspect, namely, of value and admiration.

The verb can accept as its complement a noun phrase or a what-clause. For example:

ex. ... I appreciate the transparency of your answer ... (NP)

ex....Indeed, that's the correct view. I appreciate what you are saying...(what-clause)

There are 149 NP extracts compared to 7 what-clause utterances. Obviously, the phrase is common with nominal words which stand for an explanation or the reason for the performance of the speech act of thanking. Practically, in real-life situations the phrase differs from I am grateful expression in that the former illustrates, to some extent, an external feeling of gratitude when recognizing the other party's merits or positive qualities, whereas I am grateful is more of character which expresses readiness to show appreciation and is an indicator more of an internal state rather than an outward expression (Guy 1995).

\subsection{Expressions of gratitude - Bulgarian corpus (BC)}

In view of the Bulgarian database, 169 utterances were extracted, classified and analyzed. Interestingly, the English expressions I am thankful and I am grateful share the same one word-for-word translation equivalents in the Bulgarian language, that is, Blagodaren sam (Благодарен съм). There are no other translation variants in Bulgarian. However, the translation counterpart of I appreciate in Bulgarian is: Otsenyavam (Оиенявам).

The utterances were divided into two sets of data: Blagodaren sam expressions; Otsenyavam expressions.

\section{$>$ Blagodaren sam}

In both phrases in English, i.e. I am thankful, I am grateful, the performative entry is an adjective as it is in the Bulgarian translation. The latter bears the same grammatical properties of its English equivalents. The Bulgarian entry adds the same complements:

Blagodaren sam + na /prep/ + NP

/I am thankful/grateful + to /prep/ + NP/ 
ex. ....Blagodaren sam na G-n Iliyazov ...

\section{Blagodaren sam $+z a /$ prep/ + NP/clause}

/I am thankful + for /prep/ + NP/clause/

The adjective consists of four morphemes: - blag - o-dar - en. Blag and dar bear certain semantic meanings; the former refers to kindness, gentleness, whereas the latter refers to something given as a gift or present, as a token of gratitude. Indeed, the overall denotation of the word can be paraphrased in the following way: feeling thankful to someone who was/ has been so kind to do a favour or provide someone with something that he/ she is in need of.

Semantically, the Bulgarian representative entry has a broader meaning which combines the semantic aspects of thankful and grateful. Yet, it cannot reveal fully the emotional relief and the personal involvement that are distinctive in grateful. On the other hand, pragmatically, the Bulgarian entry is closer in meaning to thankful in its expressively neutral apprehension. It sounds routinized, formulaic.

Another rather essential point is that among the 114 expressions extracted from the corpus with a root morpheme - blag only 4 utterances possess the adjective blagodaren while the rest 110 become explicit in a combination:

blagodarya + to $+\boldsymbol{N P}_{\text {person }}(4$ cases $)$

blagodarya + for $+N P_{\text {other }}$ (15 cases);

blagodarya + to $+\boldsymbol{N P}_{\text {person }}+$ for $+\boldsymbol{N P}_{\text {other }}$ (91 cases):

ex. ... Blagodarya na D-r Chilingirov za izcherpatelniya otgovor ... /in Eng.: I am grateful to $\mathrm{Mr}$ Chilingirov for the in-depth answer./

The table shows the number of the respective utterances with a root morpheme -blag:

Table 4. Case distribution of 'blagodarya' expressions in EC

\begin{tabular}{|l|l|l|}
\hline expression & number of cases & percent \\
\hline blagodaren sam + to/for & 4 & $2.36 \%$ \\
\hline blagodarya + to $+\mathrm{NP}_{\text {person }}$ & 4 & $2.36 \%$ \\
\hline blagodarya + to $+\mathrm{NP}_{\text {other }}$ & 15 & $8.87 \%$ \\
\hline blagodarya + to $+\mathrm{NP}_{\text {person }}+$ for $+\mathrm{NP}_{\text {other }}$ & 91 & $53.84 \%$ \\
\hline Total & 114 & $68.63 \%$ \\
\hline
\end{tabular}

In open debate TV programmes blagodarya + to $+N P_{\text {person }}+$ for $+N P_{\text {other }}$ pattern becomes distinct. Apparently, in Bulgarian spoken debate discourse, when a speech act of gratitude is required, the interlocutors prefer to exploit phrases which address both the addressee and give explanation/ account for the particular reason which has provoked an utterance of thanking. It may 
seem that negative politeness strategies are present in the relevant cases as the speaker's freedom of choice and action are deterred, in that the speaker in order to preserve the social balance and show him/herself as a decent member of society is obliged to express politeness by performing a communicative act of gratitude. By using the exact grammatical pattern (specifying the other party and giving explanation) the utterance sounds more genuine and sincere.

\section{$>$ Otsenyavam}

There are 55 cases of the investigated item found in the corpus, which are divided into two groups: otsenyavam + NPother; otsenyavam + what (tova koeto)-clause. The table below illustrates the respective number of utterances with regard to their pattern:

\begin{tabular}{|l|l|l|}
\hline Expression & number of cases & percent \\
\hline otsenyavam + NPother & 49 & $28.99 \%$ \\
\hline otsenyavam + what (tova koeto)-clause & 6 & $3.55 \%$ \\
\hline Total & 55 & $32.54 \%$ \\
\hline
\end{tabular}

The word otsenyavam is a full verb of transitive character, non-perfective. Semantically, it matches its English counterpart denoting the lexical meaning of worth and value.

In real-life situations, in debate format shows, it becomes clear that otsenyavam $+N P_{\text {other }}$ is more favoured in that the speaker by specifying what he/ she is actually thanking for, shows respect to the high level of competence and intelligence in the addressee's answer; the speaker seems to assess the other party's utterances as being quite essential and of high value. In that case the speech act of appreciation does not fully correspond to a negative facethreatening act (threatening the speaker's negative face), which is considered to be intrinsic in speech acts of thanking, but more as a means to establish social relationships and show regard or even admiration.

\section{Results/ Key findings}

The analysis of the data based on the findings and examination of the respective expressions in both corpora indicates that:

- all performative entries share almost equal semantics and aim at expressing gratitude either to a particular person or for a particular act;

- similarities were also found between the usage and proper awareness of gratitude expressions, expressions of thanks and appreciation;

- on the other hand, the adjectives thankful and grateful do not have exact translation equivalents in Bulgarian language, instead, there is a two-in-one translation variant - blagodaren; 
- the most preferred gratitude patterns in English public debate programmes are I am grateful to $+N P$ person and I appreciate + NPother patterns which sound less formulaic and average;

- the most favoured syntactic structures in the Bulgarian set of data are: blagodarya $+n a(t o)+N P_{\text {person }}+z a($ for $)+N P_{\text {other }}$ and otsenyavam + NPother.

- In the blagodarya $+n a($ to $)+N P_{\text {person }}+z a(f o r)+N P_{\text {other }}$ pattern the main performative expression blagodarya belongs to a different class of words compared to its counterpart in English which is an adjective.

- In English debate programmes the interlocutors either specify the person or the act, whereas in Bulgarian debate formats the speakers use both in a combination which strengthens the sincerity condition and the personal attitude towards the addressee's communicative act.

- Though it is true to say that negative politeness strategies are present in the data, the explicit emotional contour and expressive nature of the preferred patterns in English and Bulgarian convey the idea that communicative acts of gratitude in public debate shows are mainly means of sustaining social relationships and showing concern/appreciation rather than means of showing that the speaker should submit his/her will to someone or something else.

\section{Conclusion and implications}

The paper will contribute positively to a more detailed study on the issues of speech acts of thanking and politeness approaches in different cultural and social contexts. The qualitative and quantitative approach to the study could be used in investigating syntactic similarities and discrepancies in a cross-cultural research work. It could prove essential with Bulgarian learners of English when mastering pragmatic skills and communicative competences.

\section{References:}

Ahar, V. (2011). The effect of social status and size of imposition on the gratitude strategies of Persian and English speakers. Journal of Language Teaching and Research, 2(1), pp. $120-128$.

Aleksandrova, A. (2018). I Know Them by Name. In V. Kambovski et al. (eds.). KNOWLEDGE - International Journal. Vol. 19.3. GRAFOPROM. Bitola. 1077-1081.

Bach, K. (2004). Pragmatics and the philosophy of language. In L. R. Horn \& G. Ward (eds.), The handbook of pragmatics (463-487). Oxford: Basil Balckwell.

Biber, D., Conrad, S., \& Reppen, R. (1998). Corpus linguistics. Investigating Language Structure and Use. Cambridge: CUP. 
Eisenstein, M., \& Bodman, J. (1986). I very appreciate: Expressions of gratitude by native and nonnative speakers of American English". Applied Linguistics, 7. 67-185.

Eisenstein, M., \& Bodman, J. (1993). Expressing gratitude in American English. In G. Kasper \& S. Blum-Kulka (Eds.), Interlanguage Pragmatics (64-81) Oxford \& New York: Oxford University Press.

Guy, A. (1995). Say 'thank you': Some pragmatic constraints in conversational closings. Applied Linguistics, 16. 57-86.

Mahdi, A. H. (2010). Expressions of gratitude in American-English and Iraqi-Arabic. Nordic Journal of African Studies, 19(2): LAP LAMBERT Academic Publishing. 77-97.

Searle, J. (1969). An essay in the philosophy of language. Cambridge: Cambridge University Press.

Site.meta-Author. (n.d.). Добрите новини. Retrieved from https://www.bnt.bg/bg/a/pteki6012019

Site.meta-Author. (n.d.). Ще се запази ли управляващата коалиция в сегашния си формат? Retrieved from https://www.bnt.bg/bg/a/shche-se-zapazi-li-upravlyavashchatakoalitsiya-v-segashniya-si-format

The New Oxford dictionary of English. (2014). $2^{\text {nd }}$ edition. Oxford University Press.

Thomas, J. (1986). The dynamics of discourse: a pragmatic analysis of confrontational interaction. Unpublished PhD Thesis, Lancaster University.

Tognini-Bonelli, E. (2001). Corpus linguistics at work. Studies in Corpus Linguistics, 6. XII. John Benjamins Publishing Company. 